\title{
Using Theories to Design a Value Alignment Model for Smart City Initiatives
}

\author{
Anthea van der Hoogen ${ }^{(\bowtie)}(\mathbb{D})$, Brenda Scholtz (D), \\ and Andre P. Calitz 1 \\ Department of Computing Sciences, Nelson Mandela University, Summerstrand, \\ Port Elizabeth 6019, South Africa \\ \{anthea. vanderhoogen, brenda. scholtz, \\ andre.calitz\}@mandela.ac.za
}

\begin{abstract}
Smart city initiatives are widely becoming part of the world agenda to address crises and to identify new initiatives for countries to manage resources while providing better living conditions for all citizens. The purpose of this study was to design a model to support the alignment of value in Smart City initiatives. To address this purpose, a systematic literature review (SLR) was conducted to find what Smart City initiatives have been addressed in empirical studies, and what dimensions and factors are linked to these initiatives. The SLR also identified the stakeholders in a Smart City, and what their roles should be linked to these initiatives. Six theories were identified and used to undergird the researcher's understanding of the domains of Smart Cities, value and alignment. The concepts from these theories were then used with the SLR findings to design a conceptual model for Smart City initiatives. The proposed Value Alignment Smart City Model (VASC) can be used to plan or assess Smart City initiatives. The main contribution is the alignment of value amongst stakeholders to support the success of such initiatives. Further research is required to investigate adopting the model and empirically evaluate it.
\end{abstract}

Keywords: Dimensions $\cdot$ Factors $\cdot$ Stakeholder roles $\cdot$ Value $\cdot$ Alignment $\cdot$ Theories

\section{Introduction}

Even though there is no consensus by researchers regarding the definition of a Smart City, many agree on certain aspects that can help with the understanding of what Smart City studies are about [1]. The common component of Smart Cities reported is ICT solutions that address economic, social and environmental issues to contribute to a better quality of life for the citizens [1-3]. It is found that addressing Smart City concepts and trends through initiatives can help to reach a cohesive understanding amongst cities in the world who are trying to overcome similar or different problems [1,3]. The feasibility of Smart City initiatives is driven from the point of view that it is depending on Big Data and the Internet of Things (IoT) [1, 4]. Smart city initiatives should further incorporate technologies such as sensors where data can be collected and analysed so those who need the information can make informed decisions and manage administrative tasks [5]. 
Conventional and futuristic Smart City initiatives can still be classified or fit in the six dimensions namely Smart People, Smart Governance, Smart Economy, Smart Environment, Smart Mobility, and Smart Living [6]. These dimensions are said to characterise what a smart city should include and for each dimension there are factors that characterise the dimension's success [7]. A study on Smart City definitions identified certain factors on the importance of a Smart City and the information flow between the factors [7]. Their definition will be adopted for this study and states that:

"A Smart City is based on intelligent exchanges of information that flow between its many different subsystems. This flow of information is analyzed and translated into citizen and commercial services. The city will act on this information flow to make its wider ecosystem more resource-efficient and sustainable. The information exchange is based on a smart governance operating framework designed to make cities sustainable". Many studies have investigated endless lists of initiatives, factors and technologies in Smart City research fields. Some studies have also addressed instruments for assessing the alignment of value and the practices of creating value [8-10]. However, few studies have assessed the perceived value by stakeholders amongst these initiatives according to the theories found for Smart Cities, theories for value and theories for alignment. The research question this study will investigate is "What appropriate theoretical concepts can be used that will help to build a conceptual model to support the alignment of value in Smart City initiatives?".

The data value chain is seen as an important component within the conceptual model to ensure that data for each initiative can be identified for all the stakeholder interest. The rest of the paper starts with the research design (Sect. 2) followed, by findings from the dimensions and factors of a Smart City (Sect. 3). The stakeholders are perceived as a critical component in Smart City (Sect. 3.3). For this reason, it is even more important to identify the value created for each stakeholder that can ensure alignment between all the stakeholders' interests (Sect. 4). The proposed Value Alignment Smart City model (VASC) includes the components that can form part of a Smart City to achieve success in projects (Sect. 5). Finally, conclusions and future research are provided (Sect. 6).

\section{Research Design}

The research approach used to answer the research question was a systematic literature review (SLR) [11]. The journal articles, conference papers and reports were selected from Google Scholar, Google, and Research Gate. Only studies that cited real examples of Smart City initiatives were considered in the review. White papers and reports were excluded from the SLR. Only papers that were published between 2011 and 2018 were included, since it was shown by [12] that Smart City research started to boom from 2010 onward. The SLR started with the identification of nine Smart City dimensions from 15 initial studies (Sect. 3.1). The keywords were derived from the research question of this study and included "smart city framework", "smart city initiative", and "smart city dimension". The second round of the SLR included the identification of 39 related factors across all nine dimensions only from empirical studies included in the first round and the findings are summarized (available on request). The second round 
eliminated non-empirical studies and the final list of 12 studies was used as part of the analysis (available on request). The third round of the SLR helped to identify 58 stakeholder types across four stakeholder roles namely: Enabler; Provider; Utiliser and User. The final list of stakeholder types was reduced to 30 types after eliminating any duplications across the studies included in the analysis (available on request).

Finally, theories from the three domains namely Smart Cities, Value, and Alignment were investigated (Table 1). Six theories were identified as relevant and used together with the SLR findings to guide the selection of the components for the VASC model. A summary of these theories and the related components are listed in Table 1.

Table 1. Theoretical concepts informing the VASC model

\begin{tabular}{|c|c|c|}
\hline Domain & Theoretical concepts & Component of the VASC model \\
\hline \multirow[t]{3}{*}{$\begin{array}{l}\text { Smart } \\
\text { Cities } \\
\text { (SLR) }\end{array}$} & $\begin{array}{l}\text { Hexagonal Dimension } \\
\text { Theory }[6,13]\end{array}$ & $\begin{array}{l}\text { Original dimensions: Smart People; Smart } \\
\text { Governance; Smart Economy; Smart Environment; } \\
\text { Smart Mobility; and Smart Living }\end{array}$ \\
\hline & $\begin{array}{l}\text { Strategic Priority Areas } \\
\text { Theory [14] }\end{array}$ & $\begin{array}{l}\text { Extra dimensions: Smart Policy; Smart } \\
\text { Organisation; and Smart Technology-and-ICT } \\
\text { Infrastructure }\end{array}$ \\
\hline & $\begin{array}{l}\text { Triple Helix Model } \\
\text { Theory [15] }\end{array}$ & Stakeholder roles and types \\
\hline Value & $\begin{array}{l}\text { Complex Value } \\
\text { Typology Theory [16] }\end{array}$ & $\begin{array}{l}\text { Five phases of benefits realisation for all } \\
\text { stakeholders } \\
\text { Data Value Chain: data gathered and converted into } \\
\text { beneficial information across all areas within a Smart } \\
\text { City }\end{array}$ \\
\hline \multirow[t]{2}{*}{ Alignment } & $\begin{array}{l}\text { Strategic Perspective of } \\
\text { Alignment [17-19] }\end{array}$ & $\begin{array}{l}\text { Strategic initiatives of Smart City projects aligned } \\
\text { to all components of the model }\end{array}$ \\
\hline & $\begin{array}{l}\text { Structural Alignment } \\
\text { Theory }[19,20]\end{array}$ & $\begin{array}{l}\text { Alignment of roles/responsibilities of Smart City } \\
\text { structures for all stakeholders }\end{array}$ \\
\hline
\end{tabular}

The Hexagonal Dimension Theory (HDT) was selected from the Smart City domain and proposes the first six dimensions for the VASC model [6, 13]. The HDT is based on models discussing the analysis, relationships, and indicators of the six Smart City dimensions from [6]. Indicators that should be used for assessment to help determine how Smart Cities are ranked are proposed by [13, 22]. Three additional dimensions were selected as part of the VASC model, based on the Strategic Priority Areas Theory (SPAT) [14]. The additional dimensions in this study are Smart Policy; Smart Organisation, and Smart Technology-and-ICT Infrastructure [23]. The Triple Helix Model Theory (THMT) [15], emphasises the importance of the core stakeholders roles and types such as academia, industry, and government, which are key component of any national or multi-national innovation strategy and therefore any Smart City initiatives. The Complex Value Typology Theory (CVTT) was used to guide the researcher's understanding of value [16]. In this theory, value can be viewed as the nature of the benefits incurred by the stakeholders. Therefore the five phases of 
benefits' realisation [24], are important to be able to identify the potential benefits of all stakeholders in a Smart City initiative. Since one of the key elements of all the technologies involved in a Smart City is the data, the data value chain is extremely relevant for providing value to the stakeholders or for assessing where value is realised. The Strategic Perspective of Alignment (SPA) theory was used to guide the researcher's understanding of alignment and the Structural Alignment Type (SAT) theory was incorporated to align performance of Smart City initiatives between IT strategy and the organisational strategy [25]; as reported in [17-19]. SAT is a type of alignment based on a systematic view of a structure to ensure that strategic goals are achieved [20, 21]. The importance of having structures in place for a Smart City is important as well as to achieve the strategic goals within those structures because from these structures clear roles and responsibilities can be aligned between the stakeholders of Smart City initiatives.

\section{Findings: Smart City Dimensions and Factors}

In this section, the term dimension(s) will be used to describe the list of dimensions highlighted in Sect. 3.1. Any other aspects that are further used to describe these dimensions will be referred to as factors and these are described in Sect. 3.2.

\subsection{Dimensions}

The first round of the SLR resulted in the findings summarised in Table 2 relating to dimensions referred to in the empirical studies reviewed. The importance of considering the dimensions in a Smart City initiative was confirmed and that measures should be in place to ensure that cities continue to find smarter ways of dealing with challenges $[7,26]$. The studies are listed in chronological order (Table 2). The ' $x$ ' in Table 2 represents the dimensions that are applied or mentioned in the relevant empirical study as a contributor in a Smart City and the frequency (f) of citations for each dimension is provided. The first six dimensions (D1-D6) of Smart Cities were identified by [22] and [6] and are Smart People, Smart Governance, Smart Economy, Smart Environment, Smart Mobility, and Smart Living. These were extended by three dimensions (D7-D9) proposed by [23], namely Smart Policy, Smart Organisation, and Smart Technologyand-ICT Infrastructure. Each dimension in the VASC model (Fig. 1) was classified as either a core dimension or a support dimension. Smart People (D1) and Smart Technology-and-ICT Infrastructure (D9) are classified as support dimensions to the other core dimensions (D2-D8). This classification was based on the description of Porter's value chain according to the support activities or functions in an organisation [27], where the well-known support functions in an organisation include IT and Human Resource Management. The only studies that reported on all nine dimensions were [28] and [29]. Smart economy and smart living were the top two dimensions reported on ( $f=11$ ). Smart people, smart policy and smart technology-and-ICT infrastructure are the second-highest dimensions reported $(f=10)$. The dimensions that were least reported on within its context of being applied within Smart Cities are smart mobility and smart organisation. Smart People (D1) is the first important dimension identified by 
several Smart City studies [6, 23, 28-33]. This dimension recognises that people who are stakeholders can contribute to a Smart City's success. The second last row in Table 2 indicates the total number of studies per dimension where " $x$ " number of factors are found, i.e. not all dimensions have factors linked to each per empirical study.

Table 2. Comparison of studies of Smart City dimensions (Author's construct)

\begin{tabular}{|c|c|c|c|c|c|c|c|c|c|c|}
\hline \multirow{2}{*}{$\begin{array}{l}\text { Dimension } \\
\text { (D) }\end{array}$} & $\mathrm{Dl}$ & D2 & D3 & D4 & D5 & D6 & D7 & D8 & D9 & \multirow[b]{2}{*}{$\begin{array}{c}\text { Total } \\
\text { number o } \\
\text { dimension }\end{array}$} \\
\hline & $\begin{array}{l}\text { SMART } \\
\text { PEOPLE }\end{array}$ & $\begin{array}{c}\text { SMART } \\
\text { GOVERNANCE }\end{array}$ & $\begin{array}{c}\text { SMART } \\
\text { ECONOMY }\end{array}$ & $\begin{array}{c}\text { SMART } \\
\text { ENVIRONMENT }\end{array}$ & $\begin{array}{c}\text { SMART } \\
\text { MOBILITY }\end{array}$ & $\begin{array}{l}\text { SMART } \\
\text { LIVING }\end{array}$ & $\begin{array}{l}\text { SMART } \\
\text { POLICY }\end{array}$ & $\begin{array}{c}\text { SMART } \\
\text { ORGANISATION }\end{array}$ & $\begin{array}{c}\text { SMART } \\
\text { TECHNOLOGY \& } \\
\text { ICT } \\
\text { INFRASTRUCTURE }\end{array}$ & \\
\hline$[6]$ & $\mathrm{x}$ & $\mathrm{x}$ & $\mathrm{x}$ & $\mathrm{x}$ & $\mathrm{x}$ & $\mathrm{x}$ & & & & 6 \\
\hline [30] & & & & & & & $\mathrm{x}$ & $\mathrm{x}$ & $\mathrm{x}$ & 3 \\
\hline [37] & $\mathrm{x}$ & $\mathrm{x}$ & $\mathrm{x}$ & & $\mathrm{x}$ & $\mathrm{x}$ & $\mathrm{x}$ & $\mathrm{x}$ & $\mathrm{x}$ & 8 \\
\hline [23] & $\mathrm{x}$ & $\mathrm{x}$ & $\mathrm{x}$ & $\mathrm{x}$ & & & $\mathrm{x}$ & $\mathrm{x}$ & $\mathrm{x}$ & 7 \\
\hline [39] & $\mathrm{x}$ & $\mathrm{x}$ & $\mathrm{x}$ & $\mathrm{x}$ & $\mathrm{x}$ & $\mathrm{x}$ & & & & 6 \\
\hline [2] & $\mathrm{x}$ & $\mathrm{x}$ & $\mathrm{x}$ & $\mathrm{x}$ & $\mathrm{x}$ & $\mathrm{x}$ & & & & 6 \\
\hline [33] & $\mathrm{x}$ & $\mathrm{x}$ & $\mathrm{x}$ & $\mathrm{x}$ & & $\mathrm{x}$ & & & & 5 \\
\hline [28] & $\mathrm{x}$ & $\mathrm{x}$ & $\mathrm{x}$ & $\mathrm{x}$ & $\mathrm{x}$ & $\mathrm{x}$ & $\mathrm{x}$ & $\mathrm{x}$ & $\mathrm{x}$ & 9 \\
\hline [35] & & & $\mathrm{x}$ & $\mathrm{x}$ & & $\mathrm{x}$ & $\mathrm{x}$ & & $\mathrm{x}$ & 5 \\
\hline [29] & $\mathrm{x}$ & $\mathrm{x}$ & $\mathrm{x}$ & $\mathrm{x}$ & $\mathrm{x}$ & $\mathrm{x}$ & $\mathrm{x}$ & $\mathrm{x}$ & $\mathrm{x}$ & 9 \\
\hline [38] & & & & & & & $\mathrm{x}$ & & $\mathrm{x}$ & 2 \\
\hline [36] & & & $\mathrm{x}$ & & & $\mathrm{x}$ & $\mathrm{x}$ & & & 3 \\
\hline [32] & $\mathrm{x}$ & & $\mathrm{x}$ & & & & $\mathrm{x}$ & $\mathrm{x}$ & $\mathrm{x}$ & 5 \\
\hline [34] & & $\mathrm{x}$ & & & $\mathrm{x}$ & $\mathrm{x}$ & $\mathrm{x}$ & & $\mathrm{x}$ & 5 \\
\hline [33] & $\mathrm{x}$ & & & $\mathrm{x}$ & & $\mathrm{x}$ & & $\mathrm{x}$ & $\mathrm{x}$ & 5 \\
\hline $\begin{array}{c}\text { Total } \\
\text { number of } \\
\text { studies }\end{array}$ & 10 & 9 & 11 & 9 & 7 & 11 & 10 & 7 & 10 & \\
\hline $\begin{array}{c}\text { Total } \\
\text { number of } \\
\text { studies with } \\
\text { factors } \\
\end{array}$ & 8 & 7 & 9 & 7 & 5 & 9 & 10 & 7 & 10 & \\
\hline
\end{tabular}

Some of the factors related to people are the level of qualification, affinity to lifelong learning, social and ethnic plurality, creativity, and synergies through partnerships and collaborations. The second dimension is Smart Governance (D2), which was identified as an important dimension that includes factors that drive a Smart City such as participation in decision-making, public and social services and transparent governance $[6,23,28-31,34]$. The third dimension commonly cited in Smart City studies is Smart Economy (D3) [6, 23, 28-32, 35, 36]. This dimension refers to activities that encourage innovation, entrepreneurship spirit, productivity and international embeddedness. Seven studies reported on the importance of Smart Environment (D4) as a dimension [6, 23, 28, 29, 31, 33, 35]. This discussion relates to factors such as: attractiveness of natural conditions, environmental protection policies and being able to have sustainable resource management, and ensuring that a city is future proof (i.e. sustainable) by having a sustainability strategy to address social-economic, political and environmental aspects of a city. Interestingly, sustainable resource management and a future proof city were reported in the same seven studies as important for a Smart City. Smart Mobility (D5) is the dimension that focuses on factors involving sustainable, innovative and safe transport systems that are accessible locally, nationally and internationally [6, 28-30, 34]. The sixth dimension (D6) is Smart 
Living, which includes factors such as cultural facilities, health conditions, individual safety, housing quality and education facilities. Smart Policy (D7) is the dimension that highlights the importance of a close relationship between a Smart City initiative and the city's policy and the importance of an innovative policy [28-30, 32, 34-38].

The Smart Organisation dimension was identified as the eighth dimension (D8), and is important since organisational culture and innovative leadership and management can influence the success of a Smart City [23, 28-30, 32, 33, 37]. The ninth dimension (D9) is Smart Technology and ICT-infrastructure and includes all the smart technologies that are used in a Smart City used for the collection and analysis of all related data. This is only possible when there is easy access and availability in the ICTinfrastructure [23, 28-30, 32-35, 37, 38].

\subsection{Factors}

Dimensions and factors should be incorporated in studies of Smart Cities, but provision should be made for other factors to be included when gathering data and findings of studies [22]. Each dimension of a Smart City can be categorised and ultimately measured in terms of a number of factors. From the second round of the SLR process, 39 factors (F1 to F39) were identified; however the details could not be included due to space constraints but are available on request. The studies of [39] and [2] were excluded from this analysis as they did not provide empirical evidence of the factors; therefore they are highlighted in Table 2.

A total of 12 empirical studies were therefore included in the analysis of the 39 factors. The first 31 factors identified for the first six dimensions were proposed by [6] and confirmed by other studies [23, 28-38], and the remaining eight factors were found in other studies (details available on request).

\subsection{Stakeholder Roles and Types}

Arguments show the utmost importance to involve all stakeholders in Smart City initiatives, to address the challenges of these initiatives [34, 37], and to lead to successful innovative solutions [23]. Stakeholders such as citizens, end-users, IT experts and policy experts are key to the architecture of a Smart City [30]. Understanding the needs and wants of all stakeholders will improve the citizen-government relationship [23]. A significant challenge faced by Smart Cities is to efficiently articulate the relationship between these stakeholders and the city management [29]. Four key roles for stakeholders were identified in [40], namely: enablers, providers, utilisers and users. Enablers create a vision, allocate resources, provide strategic leadership, and promote networking. Providers engage academics and professionals as innovators, provide innovative research and design (R\&D) methods, augment knowledge and manage knowledge distribution systematically. Utilisers create suitable products and services, set small-scale objectives derived from the vision, learn new practices to produce accessible knowledge and innovate. Users participate in experiments, empower citizens through co-creation and produce place-based experience. The third round of the SLR identified 58 relevant stakeholder types cited in 15 studies (Table 3). In these studies, common stakeholders were recognised, however on occasions different terms were 
used to refer to similar stakeholder types in Smart Cities. The studies are listed in chronological order in Table 3. Six stakeholders namely, governments in other jurisdictions, non-profits, companies, schools, universities, and citizens were identified by [23]. Five stakeholder types were identified by [39], namely users, the public, administration, vendors and government. One study [41] argues that all investors (public and private) are important stakeholders. Residents and workers are amongst the stakeholders found in a Smart City [2]. It was evident in [31], that citizens are key to be engaged in Smart City projects to establish their needs, but industrial stakeholders are also important as they give the recommendations needed for new businesses. To create a sustainable city, the participation from stakeholders such as public government, NGOs, private companies and individual citizens is required [35]. Three stakeholder types were reported in [29], citizens, government, and businesses. The authors in [33], agree that citizens and government are key stakeholders. Stakeholders influencing privacy of Big Data such as data controllers, data processors, and third parties should be considered in a Smart City [38]. Open data is part of Smart Cities and the people that are involved with open data projects are stakeholders and can be used to brainstorm innovative ideas [36].

Table 3. Stakeholder types (Author's construct)

\begin{tabular}{l|l}
\hline Study & Stakeholder types (n = 58) \\
\hline$[37]$ & Governments; Firms; Non-profits; Citizens \\
\hline$[30]$ & End-users; IT experts; Policy/service domain experts; Public managers \\
\hline$[23]$ & $\begin{array}{l}\text { Governments in other jurisdictions; Non-profits; Companies; Schools; Universities; } \\
\text { Citizens }\end{array}$ \\
\hline$[39]$ & Users; Public administrations; Vendors; Government \\
\hline$[41]$ & Investors (public and private) \\
\hline$[2]$ & Residents/Citizens; Workers \\
\hline$[31]$ & Citizens; Industrial stakeholders \\
\hline$[28]$ & Performance evaluators \\
\hline$[35]$ & Public government; Private companies; NGOs; Citizens \\
\hline$[29]$ & Citizens; Government; Businesses \\
\hline$[38]$ & Individuals; Data controllers; Data processors; Third parties \\
\hline$[36]$ & $\begin{array}{l}\text { Public officials; Independent developers; Technically savvy citizens; NGOs; } \\
\text { Academic communities; Media communities }\end{array}$ \\
\hline$[32]$ & $\begin{array}{l}\text { Industrial players; Business players; Dynamic small and medium-sized enterprises } \\
\text { (SMEs); Building owners; Universities; Research \& technology organisations; Major } \\
\text { standardisation institutes; Government; Citizens; Local experts; External domain } \\
\text { experts }\end{array}$ \\
\hline$[34]$ & Citizens; City managers; Developers; Governments \\
\hline$[33]$ & Citizens; Government \\
\hline
\end{tabular}

They could be independent developers, technically savvy citizens, academic communities or non-governmental organisations. The co-creation process for Smart 
City solutions, identified by [32], reiterates the importance of the involvement of all stakeholders (industrial and business players to external domain experts) and the alignment of value to achieving Smart City success. City managers and government should provide easy accessibility and interactions for users such as developers and citizens to open datasets [34] since this should help these users to understand the datasets and to identify ways toward sustainable open data systems.

An analysis of the definitions taken from [40] for each role was used to classify each stakeholder type according to the most relevant role. This analysis resulted in the initial list of 58 stakeholder types being reduced to 30 common types (T1 to T30) across the 15 studies and the four stakeholder roles (available on request). For example company types such as private, public, firms and SMEs were combined into one type. Two stakeholder types (city mayor and think tanks/incubators) were not identified in the studies in Table 3 but were added to the final list based on the argument of [40] that they are equally important stakeholders. Citizens as stakeholders were reported in 11 of the 15 studies, making this the most popular type reported. Six studies reported government and four studies reported companies as important. It is clear that when a city wants to co-create smart solutions, many different types of stakeholders have to be considered.

\section{Alignment of Value for Benefits Realisation}

The previous sections related to the SLR findings, it is evident that the dimensions, factors and stakeholders of a Smart City should be used to assess the benefits of a Smart City initiative. However, existing Smart City studies do not explore whether or not the benefits of initiatives are realised or whether stakeholder value is considered or aligned. It is argued that what one stakeholder might view as a successful or valuable initiative may not be considered as successful or valuable to another stakeholder. In order to finalise the model so that value can be considered, the value theory of [15] was incorporated, which equates the assessment of benefit to the concept of value [16]. For example, "human wants, needs, and interest that are served by their realisation" [16].

In another study of value, the authors showed the factors influencing value cocreation established by [42] and also applied by [24]. They proposed an integrated process model for co-realisation of value, and they used a government case study in Norway to validate their approach to co-realisation of IT value in a collaborative setting. In the study of [24] the value co-creation process incorporated five phases for benefits realisation to co-create IT value. Their study contributed to value theory and showed that these phases are appropriate for new, major service development in the Norwegian government. This phased approach can be adopted in Smart City initiatives to achieve alignment of stakeholder value. The first phase is Phase 1-Articulate benefits whereby the key benefit areas, Key Performance Indicators (KPI) and goals are identified and articulated amongst all stakeholders. Potential benefit areas for new services in a Smart City were also explored. Based on the THMT and studies, as many stakeholders from the roles and types should be considered and should collaborate on services in a Smart City. The second phase is Phase 2-Plan benefits realisation where 
the registrar (i.e. Smart City project manager) assists the service owners (i.e. stakeholders) in elaborating their ideas into a detailed benefits plan with action steps to ensure that the benefits will be realised. In Phase 3-Implement plan, the service stakeholder has to implement the plan according to the benefit plan from Phase 2. In Phase 4-Measure benefits realised, the service stakeholder has to measure the benefits according to the measurements from the benefit plan in Phase 2 and report these to the registrar. Lastly, Phase 5-Evaluate benefits gaps and needs is where the registrar evaluates all the reports from all service stakeholders and decides on corrective measures to be taken where delays in services are evident.

\section{Discussion and Proposed Model}

The proposed VASC model is shown in Fig. 1 and represents the important components of a Smart City to achieve the success of a Smart City project or initiatives. The model was designed based on the SLR findings and the six theories, relating to the domains of Smart Cities, value, and alignment. The first component is the nine dimensions of a Smart City (see Fig. 1). Each dimension has several factors for determining the success of the dimension (available on request). The second component is the four stakeholder roles, which is a key component, since if the stakeholders are not considered no Smart City initiative will be successful. In order to ensure the value or benefits derived from such initiatives, five phases should be followed and are included as the third component of the model.

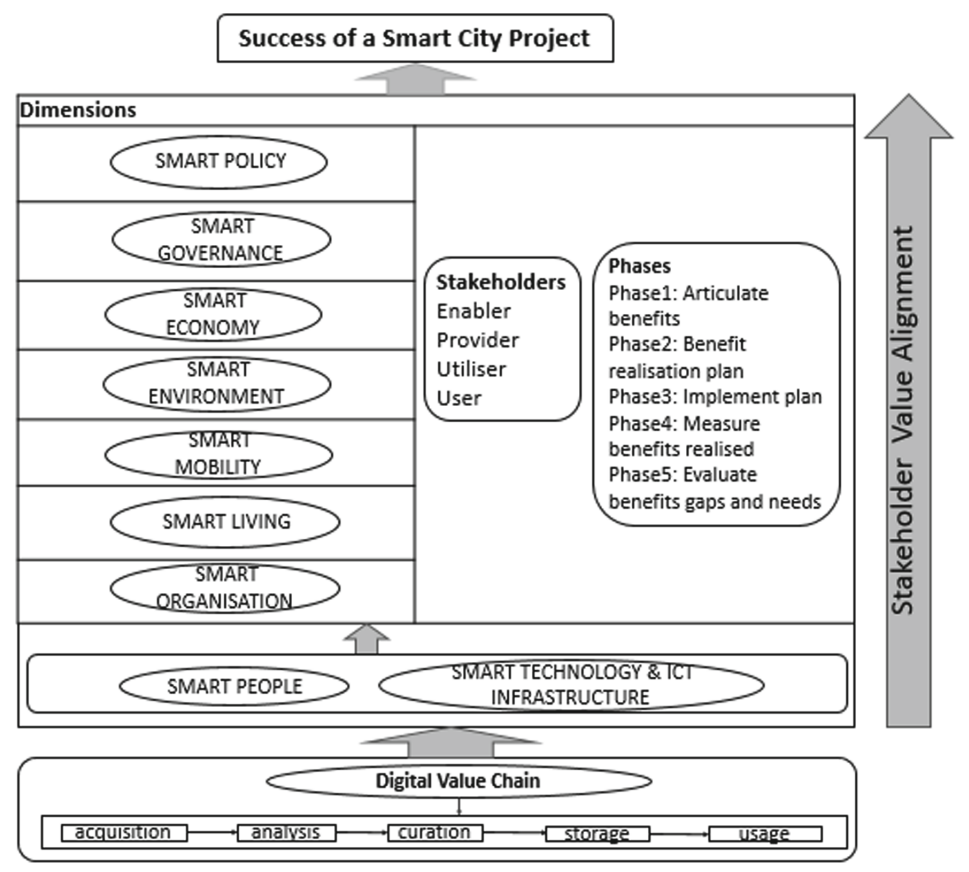

Fig. 1. VASC model 
Finally, any Smart City initiative is dependent on the information flow that supports it. Information flow is described as a "series of steps needed to generate value and useful insights from data" [43]. To obtain value from a Smart City initiative, the data value chain is therefore a crucial consideration and is the last component in the model. The data value chain includes the entire data life-cycle and involves data acquisition, analysis, curation, storage and usage so it can be used for decision making by relevant stakeholders.

\section{Conclusions}

Smart City research has made strides to making it easier to identify smarter ways of addressing real-world problems, especially with regards to the pressures of urbanisation and resource depletion. However, consensus on the definition, required components and value for Smart Cities has yet to be reached. The theoretical perspectives explored in this study can assist researchers to move closer to such consensus. The SLR conducted focused on seeking empirical studies of Smart City projects and reviewed theories that can help to address the gaps in knowledge relating to value in Smart Cities.

The study contributes to showing real-world examples in Smart Cities, and provides a comprehensive lists of factors that can be classified for each dimension. A gap in previous research was evident relating to value alignment for Smart Cities, and this study fills this gap. The contribution is the proposed VASC model, which can be used to address how value can be aligned within a Smart City for all stakeholders and dimensions. The study was limited to secondary data and future research should therefore investigate the adoption of the model in Smart City initiatives.

Acknowledgement. "This work is based on the research supported wholly/in part by the National Research Foundation of South Africa (Grant Numbers: 116779)".

\section{References}

1. Neirotti, P., De Marco, A., Cagliano, A.C., Mangano, G., Scorrano, F.: Current trends in smart city initiatives: some stylised facts. Cities 38(April), 25-36 (2014)

2. Hamzah, H., Adnan, Y.M., Daud, M.N., Alias, A., Dali, M.M.: A smart city assessment framework. In: 8th International Real Estate Researchers Symposium (IRERS), 26-28 April 2016, pp. 1-5 (2016)

3. Lu, H.P., Chen, C.S., Yu, H.: Technology roadmap for building a smart city: an exploring study on methodology. Future Gener. Comput. Syst. 97, 727-742 (2019)

4. Hashem, I.A.T., et al.: The role of big data in smart city. Int. J. Inf. Manage. 36(5), 748-758 (2016)

5. Abreu, D.P., Velasquez, K., Curado, M., Monteiro, E.: A resilient Internet of Things architecture for smart cities. Ann. des Telecommun. Telecommun. 72(1-2), 19-30 (2017)

6. Giffinger, R.: European Smart Citie: the need for a place related Understanding, Austria (2011) 
7. Albino, V., Berardi, U., Dangelico, R.M.: Smart cities: definitions, dimensions, performance, and initiatives. J. Urban Technol. 22(1), 1-19 (2015)

8. Dameri, R.P., Rosenthal-Sabroux, C.: Smart city and value creation. In: Dameri, R.P., Rosenthal-Sabroux, C. (eds.) Smart City. PI, pp. 1-12. Springer, Cham (2014). https://doi. org/10.1007/978-3-319-06160-3_1

9. Van Den Bergh, J., Dootson, P., Kowalkiewicz, M., Viaene, S.: Smart city initiatives: designing a project-level smart value assessment instrument. In: Proceedings of 19th Annual International Conference on Digital Government Research (2018)

10. Pellicano, M., Calabrese, M., Loia, F., Maione, G.: Value co-creation practices in smart city ecosystem. J. Serv. Sci. Manag. 12(01), 34-57 (2019)

11. Kitchenham, B., Pearl Brereton, O., Budgen, D., Turner, M., Bailey, J., Linkman, S.: Systematic literature reviews in software engineering - a systematic literature review. Inf. Softw. Technol. 51, 7-15 (2009)

12. Mora, L., Bolici, R., Deakin, M.: The first two decades of smart-city research: a bibliometric analysis. J. Urban Technol. 24(1), 3-27 (2017)

13. Kishore, A.N.N., Sodh, Z.: Exploratory research on smart cities: theory, policy and practice, New Delhi (2015)

14. Allwinkle, S., Cruickshank, P.: Creating smarter cities: an overview. J. Urban Technol. 18 (2), 1-16 (2011)

15. Etzkowitz, H., Leydesdorff, L.: The triple helix-university-industry-government relations: a laboratory for knowledge based economic development. EASST Rev. 14(1), 14-19 (1995)

16. Rescher, N.: Introduction to Value Theory. Prentice-Hall Inc., Englewood Cliffs (1969)

17. Avison, D., Jones, J., Powell, P., Wilson, D.: Using and validating the strategic alignment model. J. Strateg. Inf. Syst. 13, 223-246 (2004)

18. Campbell, B., Kay, R., Avison, D.: Strategic alignment: a practitioner's perspective. J. Enterp. Inf. Manag. 18(6), 653-664 (2005)

19. Burn, J.M., Szeto, C.: A comparison of the views of business and IT management on success factors for strategic alignment. Inf. Manag. 37, 197-216 (2000)

20. Chorn, N.H.: The 'alignment' theory: creating strategic fit. Manag. Decis. 29(1), 20-24 (1991)

21. Torraco, R.J., Swanson, R.A.: The strategic roles of human resource development. J. Eur. Ind. Training 18(4), 10-21 (1995)

22. Giffinger, R., Fertner, C., Kramar, H., Kalasek, R., Milanovic, N.P., Meijers, E.: Smart Cities Ranking of European Medium-Sized Cities, pp. 13-18. Centre of Regional Science (SRF), Vienna University of Technology, Vienna (2007)

23. Alawadhi, S.: Building understanding of smart city initiatives. In: Scholl, H.J., Janssen, M., Wimmer, M.A., Moe, C.E., Flak, L.S. (eds.) EGOV 2012. LNCS, vol. 7443, pp. 40-53. Springer, Heidelberg (2012). https://doi.org/10.1007/978-3-642-33489-4_4

24. Flak, L.S., Solli-Saether, H., Straub, D.: Towards a theoretical model for co-realization of IT value in government. In: Proceedings of the 2015 48th Annual Hawaii International Conference on System Sciences, 05-08 January 2015, pp. 2486-2494 (2015)

25. Rose, K., Shuck, B., Bergman, M.: Unpacking organizational alignment: the view from theory and practice. J. Organ. Learn. Leadersh. 13(1), 18-31 (2015)

26. Cocchia, A.: Smart and digital city: a systematic literature review. In: Dameri, R.P., Rosenthal-Sabroux, C. (eds.) Smart City. PI, pp. 13-43. Springer, Cham (2014). https://doi. org/10.1007/978-3-319-06160-3_2

27. Porter, M.E.: Competitive Advantage: Creating and Sustaining Superior Performance. Free Press, New York (1985)

28. Khatoun, R., Zeadally, S.: Smart cities: concepts, architectures, research opportunities. Commun. ACM 59(8), 46-57 (2016) 
29. Calderón, M., López, G., Marín, G.: Smart cities in Latin America. In: Ochoa, S.F., Singh, P., Bravo, J. (eds.) UCAmI 2017. LNCS, vol. 10586, pp. 15-26. Springer, Cham (2017). https://doi.org/10.1007/978-3-319-67585-5_2

30. Nam, T., Pardo, T.: Conceptualizing smart city with dimensions of technology, people, and institutions. In: Proceedings of the 12th Annual International Conference on Digital Government Research, pp. 282-291 (2011)

31. Huovila, A., Airaksinen, M., Pinto-Seppa, K.P., Penttinen, T.: Smart city performance measurement system. In: 41st IAHS World Congress: Sustainability and Innovation for the Future, 13-16 September 2016, pp. 1-11 (2016)

32. Wendt, W., Dübner, S.: Co-creation for smart city solutions - a peer-to-peer process. In: REAL CORP 2017 Proceedings, 12-14 September 2017, vol. 6, pp. 99-108 (2017)

33. Manupati, K.V., Ramkumar, M., Samanta, D.: A multi-criteria decision making approach for the urban renewal in Southern India. Sustain. Cities Soc. 42, 471-481 (2018)

34. Yadav, P., Hasan, S., Ojo, A., Curry, E.: The role of open data in driving sustainable mobility in nine smart cities. In: 25th European Conference on Information Systems (ECIS 2017), Guimarães, Portugal, 5-10 June 2017, pp. 1248-1263 (2017)

35. Spaans, M., Waterhout, B.: Building up resilience in cities worldwide - Rotterdam as participant in the 100 Resilient Cities Programme. Cities 61, 109-116 (2016)

36. Kassen, M.: Understanding transparency of government from a Nordic perspective: open government and open data movement as a multidimensional collaborative phenomenon in Sweden. J. Glob. Inf. Technol. Manag. 20(4), 236-275 (2017)

37. Nam, T., Pardo, T.: Smart city as urban innovation: focusing on management, policy, and context. In: Proceedings of the 5th International Conference on Theory and Practice of Electronic Governance, pp. 185-194 (2011)

38. Garg, R., Schmitt, C., Stiller, B.: Information policy dimension of emerging technologies, 30 March 2017. https://ssrn.com/abstract=2943451. https://doi.org/10.2139/ssrn.2943451

39. Balakrishna, C.: Enabling technologies for smart city services and applications. In: Proceedings - 6th International Conference on Next Generation Mobile Applications, Services, and Technologies, NGMAST, pp. 223-227 (2012)

40. Mayangsari, L., Novani, S.: Multi-stakeholder co-creation analysis in smart city management: an experience from Bandung, Indonesia. Procedia Manuf. 4, 315-321 (2015)

41. Monzon, A.: Smart cities concept and challenges: bases for the assessment of smart city projects. In: Helfert, M., Krempels, K.-H., Klein, C., Donnellan, B., Gusikhin, O. (eds.) Smart Cities, Green Technologies, and Intelligent Transport Systems. CCIS, vol. 579, pp. 17-31. Springer, Cham (2015). https://doi.org/10.1007/978-3-319-27753-0_2

42. Sarker, S., Sarker, S., Sahaym, A., Bjørn-Andersen, N.: Exploring value cocreation in relationships between an ERP vendor and its partners: a revelatory case study. MIS Q. 36(1), 317-338 (2012)

43. Curry, E.: The big data value chain: definitions, concepts, and theoretical approaches. In: Cavanillas, J., Curry, E., Wahlster, W. (eds.) New Horizons for a Data-Driven Economy, pp. 29-37. Springer, Cham (2016). https://doi.org/10.1007/978-3-319-21569-3_3 